\title{
Efficacy of nanostructured silica as a stored pulse protector against the infestation of bruchid beetle, Callosobruchus maculatus (Coleoptera: Bruchidae)
}

\author{
Ganesh Arumugam $^{1} \cdot$ Veeramani Velayutham $^{1} \cdot$ Sakthivelkumar Shanmugavel $^{1}$. \\ Janarthanan Sundaram ${ }^{1}$
}

Received: 19 March 2015 / Accepted: 3 April 2015/Published online: 12 April 2015

(c) The Author(s) 2015. This article is published with open access at Springerlink.com

\begin{abstract}
The treatment of hydrophobic silica nanoparticles (SNPs) with the pulse seeds of Cajanus cajan, Macrotyloma uniflorum, Vigna mungo, Vigna radiata, Cicer arietinum and Vigna unguiculata against the infestation of stored pulse beetle, Callosobruchus maculatus revealed a significant reduction in oviposition, adult emergence and seed damage potential. There was a complete retardation of growth of this beetle in the treated seeds of $C$. cajan. SNPtreated seeds of these six varieties of pulses revealed no effect on the growth of seeds as revealed by seed germination, growth rate of root and shoot. Similarly, the soil microflora measured in terms of colony forming units was not affected by silica nanoparticles upon its treatment with pulse seeds. The results of this study thus clearly demonstrated the useful nature of silica nanoparticles as seed protecting agent for the control of $C$. maculatus.
\end{abstract}

Keywords Silica nanoparticles - Pulses - Insect pest control - Bruchid beetle $\cdot$ Callosobruchus maculatus

\section{Introduction}

Pulses are considered as an important source of protein for human consumption in many regions of world. Bruchid beetle, Callosobruchus maculatus (Fabricius) is a major stored product pest responsible for considerable damage in stored pulses and make the pulses unfit for human consumption (Singh and Jackai 1985). This situation necessitated

Janarthanan Sundaram

sundaram.janarthanan@gmail.com; janas_09@yahoo.co.in

1 Unit of Entomology, Department of Zoology, University of Madras, Guindy Campus, Chennai 600025, India application of some control measures in order to minimize the losses caused by this stored product pest. One of the age-old traditions in stored pulse insect pest control was coating the seeds with either finely powdered wet red soil or diatomaceous earths as protective agent or abrasive by different ethnic races all over the world (Ebeling 1971; Golob 1997). Much larger quantities of amorphous silica dust are later used to control the adult bean bruchids (Giga and Chinwada 1994). The insecticidal activity to an extent of $80 \%$ using polyethylene glycol-coated nanoparticles loaded with garlic essential oil against Tribolium castaneum was already carried out in processed stored products (Yang et al. 2009). The application of diverse kinds of nanoparticles for the control of rice weevil, Sitophilus oryzae was also studied (Goswami et al. 2010). Further, studies by Rouhani et al. (2012) reported that the silica and silver nanoparticles with a particle size range 20-60 nm was much effective on larvae than adults of C. maculatus. Compared to commercially available insecticides, inorganic nanostructured materials may provide an inexpensive and dependable alternative for stored product insect pest control. The property or efficacy of nanoparticles primarily lies based on their size. As a result, lesser quantities of nano-sized particles cover a large surface area (Goswami et al. 2010). This research background formed the basis for present study to test the efficacy of hydrophobic nanostructured silica with a much less particle size $(12 \mathrm{~nm})$ as a novel pulse seed protecting agent towards the infestation of stored pulse insect pest, $C$. maculatus.

\section{Materials and methods}

Hydrophobic silica nanoparticles (Sigma-Aldrich) with a particle size of $12 \mathrm{~nm}$ were used for the experiments. Seeds of clean and infestation-free red gram (Cajanus cajan), horse gram 
(Macrotyloma uniflorum), black gram (Vigna mungo), green gram (Vigna radiata), chick pea (Cicer arietinum) and cow pea (Vigna unguiculata) were purchased from local market and used in the experiments. Stock culture of $C$. maculatus (Coleptera: Bruchidae) was maintained on these seeds at $28 \pm 2{ }^{\circ} \mathrm{C}$ in glass jars covered with muslin cloth. Seeds (500 g) were then conditioned at $28 \pm 2{ }^{\circ} \mathrm{C}$ and $70 \%$ relative humidity for a period of 10 days for feeding bioassays. The pulse seed varieties in each treatment were mixed individually with dusts of SNPs at different concentrations $(500,600,700,800,900,1000$ ppm) in glass jars. The jars were shaken manually for few times to achieve equal distribution of SNPs on the seeds under controlled conditions. Each variety of seeds treated with SNPs was kept in glass vials covered with muslin cloth. It was then introduced with two pairs of newly emerged adults of $C$. maculatus from the stock culture for oviposition. Replicates were maintained for each variety. A suitable control was also maintained. The numbers of eggs laid on the seeds of each variety was counted after 5 days. These eggs were allowed to develop and emerge into adults. Developmental period, percentage of adult emergence and seed damage potential [(initial - final)/initial seed weight $\times 100$ ] were calculated to evaluate the developmental performance of $C$. maculatus on these pulses. The $\mathrm{LC}_{50}$ (ppm) and $95 \%$ confidence limits (95\% CLs) were calculated by probit analysis (Finney 1971).

The SNP-treated seeds and bruchid beetles exposed to these seeds were subjected to scanning electron microscope (Hitachi S-3400 scanning electron microscope at $15.0 \mathrm{kV}$ ). The specimens were mounted on holders, examined and photographs were taken.

To verify the influence of nanoparticle treatment on seeds, the six varieties of seeds treated with SNPs and untreated seeds were germinated on soil and maintained at laboratory conditions. Germination and development of roots of both untreated and nanoparticle-treated seeds were observed after 4 days. Then, the germination was halted, seed germination rate was calculated. Seedling shoot and root lengths were also measured.

Soil sample was collected from the nearby university garden and total number of culturable soil bacteria was determined using the soil dilution plate-count technique. Fivefold dilutions of soil sample were prepared from the original soil suspension and the dilutions were plated on nutrient agar containing SNPs at concentrations of 0.03 and $0.06 \%$. The plates were incubated at $28{ }^{\circ} \mathrm{C}$ and colonies were counted after $24 \mathrm{~h}$ of incubation.

\section{Results}

The effect of treatment of hydrophobic silica nanoparticles with the seeds of $C$. cajan, $M$. uniflorum, $V$. radiata, $V$. mungo, C. arietinum and $V$. unguiculata is presented in
Table 1. It was revealed from the results of insect bioassay that the fecundity potential of $C$. maculatus was significantly reduced in all the varieties of seeds treated with SNPs except $V$. unguiculata. But fecundity was observed even at 900 and 1000 ppm concentrations of SNP-treated seeds of $V$. unguiculata. A significant reduction in adult emergence was observed in all the treatments when compared to control. Application of hydrophobic silica nanoparticles extensively reduced the seed damage potential in all the treatments which was observed to be significant over control. It was very clearly shown in Table 1 that there were no adult development and seed damage except laying of very few numbers of eggs at the lowest concentrations of SNP-treated seeds. Treatment of SNPs with the seeds of red gram, $C$. cajan was very effective against infestation of $C$. maculatus (Table 1) and there were no eggs laid by $C$. maculatus on these seeds. SNPtreated $C$. cajan seeds were found to be more effective in the control of insect pest than $V$. mungo $\left(\mathrm{LC}_{50}-418 \mathrm{ppm}\right)$ and $M$. uniflorum $\left(\mathrm{LC}_{50^{-}}-446 \mathrm{ppm}\right)$. The SNP-treated $C$. arietinum $\left(\mathrm{LC}_{50}-576 \mathrm{ppm}\right)$ and $V$. radiata $\left(\mathrm{LC}_{50}-515 \mathrm{ppm}\right)$ revealed comparatively less effect on $C$. maculatus. The SNP-treated $V$. unguiculata $\left(\mathrm{LC}_{50}-982 \mathrm{ppm}\right)$ showed no effect even at higher concentrations of nanoparticle treatment (Table 2).

Scanning electron microscopic photographs of SNPtreated seeds indicated attachment of nanosilica on the surface of seed coat (Fig. 1b) when compared to seed coats of control seeds (Fig. 1a). Subsequent release of the bruchid adults to these nanosilica-treated seeds caused adhesion of silica nanoparticles throughout the body and abrasion on the elytra with a well pronounced scratches and splits (Figs. 1d, f, 2b) when compared to insects in control (Figs. 1c, e, 2a). Seed germination, root and shoot growths were not affected upon treatment of 500 and $1000 \mathrm{ppm}$ concentrations of SNPs (Table 3). Likewise, effect of SNPs on soil microflora showed no reduction in colony forming units (CFU) in nanosilica treatments over control (Table 4).

\section{Discussion}

An attempt was made in the present study to test the efficacy of silica nanoparticles to protect various pulse seed varieties from the infestation of stored product insect pest, C. maculatus. It was observed from the results that the seeds treated with SNPs drastically reduced the fecundity of $C$. maculatus. Suffering of adult insects due to desiccation and spiracular blockage by the exposure of silica nanoparticle could be the cause for this reduced fecundity. This could have prevented mating as the treated SNPs attach all over the body of adult beetles. Insects are supposed 
Table 1 Effect of silica nanoparticles on the infestation potential of stored product insect pest, C. maculatus

\begin{tabular}{|c|c|c|c|c|c|c|c|}
\hline & \multirow{2}{*}{$\begin{array}{l}\text { Concentration of } \\
\text { SNPs (ppm) }\end{array}$} & \multicolumn{6}{|c|}{ Seed varieties } \\
\hline & & C. cajan & M. uniflorum & V. mungo & V. radiata & C. arietinum & V. unguiculata \\
\hline \multirow[t]{7}{*}{ Fecundity (no. of eggs/female) } & 0.00 & $46 \pm 2.0$ & $24 \pm 3.0$ & $28 \pm 3.0$ & $23 \pm 3.0$ & $35 \pm 2.3$ & $58 \pm 2.0$ \\
\hline & 500 & Nil & $02 \pm 2.1^{*}$ & $02 \pm 1.1^{*}$ & $11 \pm 3.0^{\mathrm{NS}}$ & $18 \pm 3.0^{\mathrm{NS}}$ & $56 \pm 3.5^{\mathrm{NS}}$ \\
\hline & 600 & Nil & $02 \pm 1.7^{*}$ & $02 \pm 1.0^{*}$ & $10 \pm 2.0^{\mathrm{NS}}$ & $12 \pm 2.2^{*}$ & $54 \pm 0.5^{\mathrm{NS}}$ \\
\hline & 700 & Nil & Nil & $02 \pm 2.0^{*}$ & $07 \pm 3.0^{\mathrm{NS}}$ & $08 \pm 2.7^{*}$ & $54 \pm 0.5^{\mathrm{NS}}$ \\
\hline & 800 & Nil & Nil & Nil & $05 \pm 2.6^{*}$ & $05 \pm 3.6^{*}$ & $45 \pm 1.0^{\mathrm{NS}}$ \\
\hline & 900 & Nil & Nil & Nil & Nil & Nil & $44 \pm 2.0^{\mathrm{NS}}$ \\
\hline & 1000 & Nil & Nil & Nil & Nil & Nil & $44 \pm 3.0^{\mathrm{NS}}$ \\
\hline \multirow[t]{7}{*}{ Developmental period (days) } & 0.00 & $33 \pm 1.0$ & $33 \pm 1.0$ & $32 \pm 1.0$ & $32 \pm 1.0$ & $32 \pm 1.0$ & $32 \pm 1.0$ \\
\hline & 500 & Nil & Nil & Nil & $32 \pm 1.0$ & $32 \pm 1.0$ & $32 \pm 1.0$ \\
\hline & 600 & Nil & Nil & Nil & $32 \pm 1.0$ & $32 \pm 1.0$ & $32 \pm 1.0$ \\
\hline & 700 & Nil & Nil & Nil & $32 \pm 1.0$ & $32 \pm 1.0$ & $32 \pm 1.0$ \\
\hline & 800 & Nil & Nil & Nil & $32 \pm 1.0$ & $32 \pm 1.0$ & $32 \pm 1.0$ \\
\hline & 900 & Nil & Nil & Nil & Nil & Nil & $32 \pm 1.0$ \\
\hline & 1000 & Nil & Nil & Nil & Nil & Nil & $32 \pm 1.0$ \\
\hline \multirow[t]{7}{*}{ Adult emergence $(\%)$} & 0.00 & 100 & 100 & 100 & 100 & 100 & 100 \\
\hline & 500 & Nil & Nil & Nil & $35 \pm 3.40^{*}$ & $38 \pm 3.70^{*}$ & 100 \\
\hline & 600 & Nil & Nil & Nil & $24 \pm 3.00^{*}$ & $26 \pm 3.25^{*}$ & 100 \\
\hline & 700 & Nil & Nil & Nil & $10 \pm 2.20^{*}$ & $11 \pm 2.20^{*}$ & 100 \\
\hline & 800 & Nil & Nil & Nil & $06 \pm 2.00^{*}$ & $06 \pm 2.20^{*}$ & $98 \pm 0.2^{\mathrm{NS}}$ \\
\hline & 900 & Nil & Nil & Nil & Nil & Nil & $95 \pm 2.0^{\mathrm{NS}}$ \\
\hline & 1000 & Nil & Nil & Nil & Nil & Nil & $98 \pm 1.0^{\mathrm{NS}}$ \\
\hline \multirow[t]{7}{*}{ Seed damage potential (\%) } & 0.00 & $36 \pm 3.5$ & $21 \pm 3.6$ & $22 \pm 3.5$ & $19 \pm 3.5$ & $22 \pm 1.5$ & $40 \pm 3.2$ \\
\hline & 500 & Nil & Nil & Nil & $05 \pm 1.4^{\mathrm{NS}}$ & $06 \pm 1.4^{\mathrm{NS}}$ & $40 \pm 2.7^{\mathrm{NS}}$ \\
\hline & 600 & Nil & Nil & Nil & $05 \pm 2.0^{\mathrm{NS}}$ & $05 \pm 2.0^{\mathrm{NS}}$ & $40 \pm 0.5^{\mathrm{NS}}$ \\
\hline & 700 & Nil & Nil & Nil & $04 \pm 2.5^{\mathrm{NS}}$ & $04 \pm 3.5^{\mathrm{NS}}$ & $39 \pm 3.0^{\mathrm{NS}}$ \\
\hline & 800 & Nil & Nil & Nil & $01 \pm 1.3^{\mathrm{NS}}$ & $01 \pm 0.2^{\mathrm{NS}}$ & $31 \pm 2.2^{\mathrm{NS}}$ \\
\hline & 900 & Nil & Nil & Nil & Nil & Nil & $31 \pm 0.3^{\mathrm{NS}}$ \\
\hline & 1000 & Nil & Nil & Nil & Nil & Nil & $31 \pm 0.2^{\mathrm{NS}}$ \\
\hline
\end{tabular}

$N S$ non-significant

* Significant at $P<0.05$

to release a greasy layer on their body surface, which may be involved in physical interactions between the organisms especially during mating. In mating, males frequently attach to the female's dorsal body by means of their feet, where grease should play an important role for the attachment of feet (Voigt et al. 2009). This could have caused incomplete mating in the case of lower concentrations and prevented mating at higher concentrations of SNPs treatment. It was not only desiccation or blockage of spiracles, but also the surface enlargement of the integument as a consequence of dehydration.

Further it is projected that insecticidal efficacy of the dust becomes enhanced if the particles are finely divided. This was also evident from our experiment that even at low concentrations of SNPs, as the size of the particle was $12 \mathrm{~nm}$ it enormously increased exposed surfaces of the
Table 2 Probit analysis performed on mortality data of SNP-exposed C. maculatus

\begin{tabular}{ll}
\hline Pulses & LC $_{50}(95 \% \mathrm{CL})^{\mathrm{a}}(\mathrm{ppm})$ \\
\hline M. uniflorum & $418(373-497)$ \\
V. mungo & $446(373-497)$ \\
V. radiata & $515(444-563)$ \\
C. arietinum & $576(444-563)$ \\
V. unguiculata & $982(869-1015)$
\end{tabular}

${ }^{\mathrm{a}} \mathrm{LC}_{50}$ values are after $24 \mathrm{~h}$

seeds which could interact with the insects. Such a kind of observation was not made with the seeds of cow pea ( $V$. unguiculata). It could be attributed that physical characteristics of seeds also an important factor for the attachment 
of nanoparticles on their surface. Texture and size of $V$. unguiculata seed coat might influence the nanoparticle attachment. One possibility is that the rough nature of the seeds of $V$. unguiculata might have lead to poor attachment of SNPs with the seed coat. The other possible reason could have been the larger size of these seeds over other seeds including seeds of $C$. arietinum. It should have actually required more quantities of SNPs for effective protection in the seeds of $V$. unguiculata. The scanning electron microscopic studies of the insects introduced into the nanosilica- treated seeds clearly showed attachment of nanoparticles all over the body of bruchid beetles with scratches and splits on the cuticle. This subsequently lead to the loss of water through dehydration as the water barrier is damaged and die out of desiccation as reported by Ebeling (1971). Damage could have occurred to the protective wax coat on the cuticle of insects, both by sorption and abrasion (Debnath et al. 2011). It is believed that this hypothesis for the physical mode of action makes the use of nanocides stronger for the control of storage pests. As a result, it is
Fig. 1 Scanning electron microscopic photographs of SNPs exposed seeds and $C$. maculatus. a Control seed coat of green gram, b SNP-treated seed coat, $\mathbf{c}$ dorsal view of untreated insect, $\mathbf{d}$ dorsal view of SNP-exposed insect, e ventral view of untreated adult and f ventral view of SNP-exposed insect
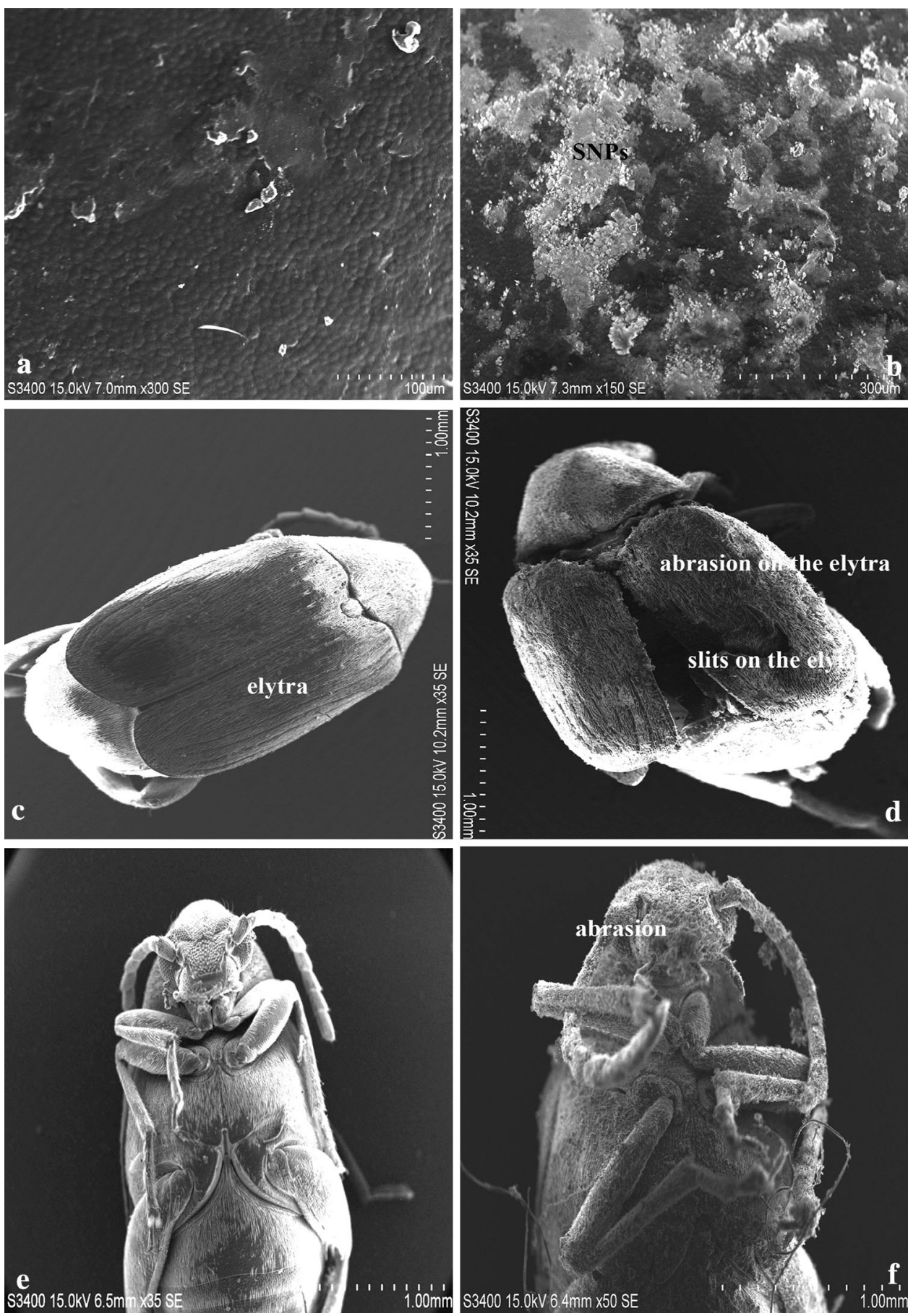
Fig. 2 Scanning electron microscopic photographs of a dorsal view of elytra of control insect and $\mathbf{b}$ dorsal view of elytra of SNP-treated insect caused abrasion and damage on the elytra
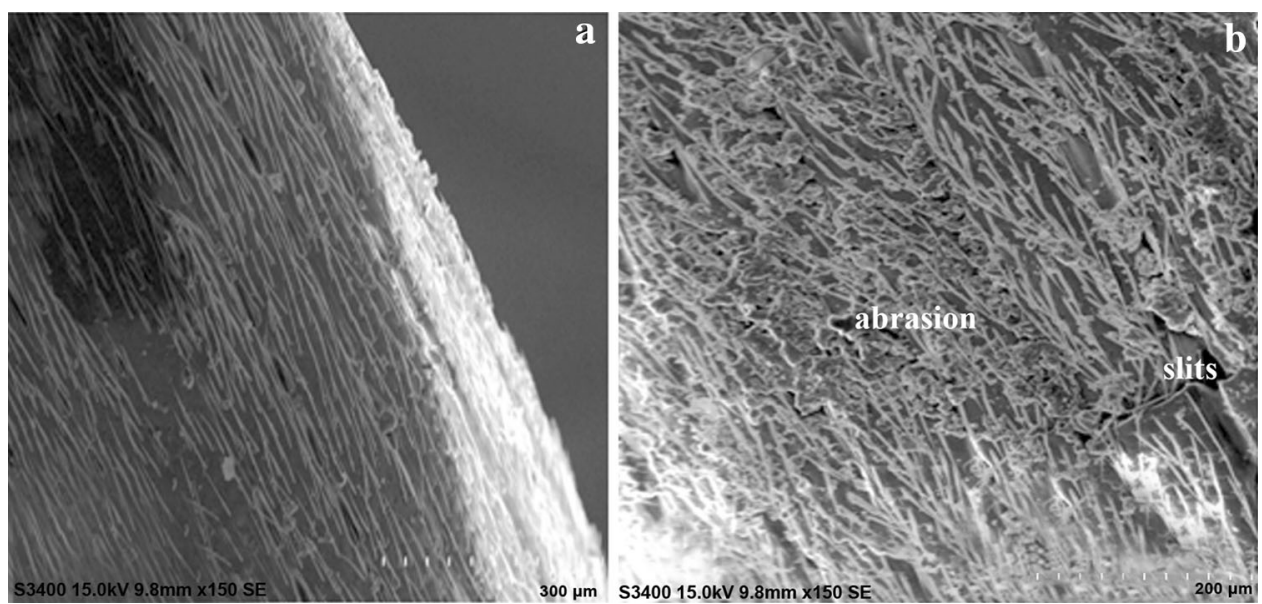

Table 3 Effect of SNP-treated seeds on germination and growth of various pulse seeds

\begin{tabular}{|c|c|c|c|c|c|c|c|}
\hline & \multirow{2}{*}{$\begin{array}{l}\text { Concentration of } \\
\text { SNPs (ppm) }\end{array}$} & \multicolumn{6}{|l|}{ Seed varieties } \\
\hline & & C. cajan & M. uniflorum & V. mungo & $V$. radiata & C. arietinum & V. unguiculata \\
\hline \multirow[t]{3}{*}{ Germination (\%) } & 0.0 & 100 & 100 & 100 & 100 & 100 & 100 \\
\hline & 500 & 100 & 100 & 100 & 100 & 100 & 100 \\
\hline & 1000 & 100 & 100 & 100 & 100 & 100 & 100 \\
\hline \multirow[t]{3}{*}{ Shoot length $(\mathrm{cm})$} & 0.0 & $11.2 \pm 0.3^{\mathrm{NS}}$ & $8.6 \pm 0.6^{\mathrm{NS}}$ & $10.6 \pm 0.4^{\mathrm{NS}}$ & $10.8 \pm 0.5^{\mathrm{NS}}$ & $8.2 \pm 0.8^{\mathrm{NS}}$ & $10.2 \pm 0.5^{\mathrm{NS}}$ \\
\hline & 500 & $11.5 \pm 0.2^{\mathrm{NS}}$ & $8.4 \pm 0.3^{\mathrm{NS}}$ & $10.7 \pm 0.5^{\mathrm{NS}}$ & $10.8 \pm 0.2^{\mathrm{NS}}$ & $8.5 \pm 0.2^{\mathrm{NS}}$ & $10.4 \pm 0.2^{\mathrm{NS}}$ \\
\hline & 1000 & $11.8 \pm 0.8^{\mathrm{NS}}$ & $8.6 \pm 0.5^{\mathrm{NS}}$ & $11.0 \pm 0.4^{\mathrm{NS}}$ & $11.2 \pm 0.3^{\mathrm{NS}}$ & $8.5 \pm 0.1$ NS & $10.4 \pm 0.6^{\mathrm{NS}}$ \\
\hline \multirow[t]{3}{*}{ Root length $(\mathrm{cm})$} & 0.0 & $4.2 \pm 0.3^{\mathrm{NS}}$ & $2.1 \pm 0.5^{\mathrm{NS}}$ & $3.3 \pm 0.2^{\mathrm{NS}}$ & $3.2 \pm 0.4^{\mathrm{NS}}$ & $1.9 \pm 0.1 \mathrm{NS}$ & $2.8 \pm 0.7^{\mathrm{NS}}$ \\
\hline & 500 & $4.5 \pm 0.5^{\mathrm{NS}}$ & $2.1 \pm 0.2^{\mathrm{NS}}$ & $3.3 \pm 0.6^{\mathrm{NS}}$ & $3.2 \pm 0.6^{\mathrm{NS}}$ & $2.0 \pm 0.3^{\mathrm{NS}}$ & $2.8 \pm 0.3^{\mathrm{NS}}$ \\
\hline & 1000 & $4.5 \pm 0.2^{\mathrm{NS}}$ & $2.2 \pm 0.9^{\mathrm{NS}}$ & $3.6 \pm 0.1^{\mathrm{NS}}$ & $3.4 \pm 0.2^{\mathrm{NS}}$ & $2.0 \pm 0.5^{\mathrm{NS}}$ & $2.9 \pm 0.3^{\mathrm{NS}}$ \\
\hline
\end{tabular}

NS non-significant

Table 4 Effect of SNPs treatment on the growth of soil microflora

\begin{tabular}{ll}
\hline Concentration of SNPs in nutrient agar $(\%) \mathrm{w} / \mathrm{v}$ & $\left(\times 10^{5}\right) \mathrm{CFU} / \mathrm{ml}$ \\
\hline 0.00 & 34 \\
0.03 & 36 \\
0.06 & 44 \\
\hline
\end{tabular}

assumed that there would not be any genetic selection of resistance or physiological resistance to such a mechanism of action of nanocides other than behavioral response.

Though SNPs used in our experiments are amorphous in nature and silica is considered a less reactive material (Debnath et al. 2011), its toxicity on the germination and growth of pulse seed varieties upon SNPs treatment was carried out. In such phytotoxic studies, seed coats play a very important role in protecting the embryo and can have selective permeability to the external factors (Wierzbicka and Obidzinska 1998). In this study, seed germination was not at all affected by the treatment of SNPs at 500 and $1000 \mathrm{ppm}$ concentrations and that showed no alterations in the seed coat towards the treatment of nanoparticles. Many nanoparticles have already been reported to have antimicrobial properties and thus directly affect microorganisms (Shah and Belozerova 2009). Even though silica is most abundant mineral in the earth crust, the nano-sized silica may be harmful to microflora present in the soil. But our results clearly showed that there was no negative impact of colony forming units of soil samples on the agar media treated with silica nanoparticles. No experiments were conducted so far for large-scale application of SNPs to pulses without loss of particles in air. The removal of silica nanoparticles from the seeds prior to further processing was also not attempted. It is thus planned to carry out these aspects of study before application of the potential use of nanoparticles for stored product pest control.

\section{Conclusion}

This study is the first effort in the utilization of nano-scale silica as protective agent or abrasive used to coat various seeds of pulses against infestation by stored product pests 
like $C$. maculatus. An attempt is made here to use only the effective dose of nanosilica at its minimum concentration to apply on the seeds of pulses. It was observed from the study that the physical characteristics of seeds play a significant role in limiting the coating or covering maximum surface area on the seeds by nanosilica. It was interesting to observe such a phenomenon in a seed variety, $V$. unguiculata, where the nanosilica coating was not much influenced by the surface properties and thus seeds were not protected from the infestation of C. maculatus. However, majority of the seeds were protected from the infestation of pest insect with the treatment of nanosilica. This indicated the efficacy of nanostructured silica as a tool in stored product pest control.

Acknowledgments The authors gratefully acknowledge the financial support received from NCNST, University of Madras.

Conflict of interest The authors declare that they have no conflict of interest.

Open Access This article is distributed under the terms of the Creative Commons Attribution 4.0 International License (http:// creativecommons.org/licenses/by/4.0/), which permits unrestricted use, distribution, and reproduction in any medium, provided you give appropriate credit to the original author(s) and the source, provide a link to the Creative Commons license, and indicate if changes were made.

\section{References}

Debnath N, Das S, Seth D, Chandra R, Bhattacharya S, Goswami A (2011) Entomotoxic effect of silica nanoparticles against Sitophilus oryzae (L.). J Pest Sci 84:99-105
Ebeling W (1971) Sorptive dusts for pest control. Annu Rev Entomol $16: 123-158$

Finney DJ (1971) Probit analysis, 3rd edn. Cambridge University Press, London

Giga DP, Chinwada P (1994) Efficacy of an amorphous silica dust against bean bruchids. In: Proceedings of the 6th International conference on stored-product protection, vol 2

Golob P (1997) Current status and future perspectives for inert dusts for control of stored product insects. J Stored Prod Res 18:67-74

Goswami A, Roy I, Sengupta S, Debnath N (2010) Novel applications of solid and liquid formulations of nanoparticles against insect pests and pathogens. Thin Solid Films 519:252-1257

Rouhani M, Samih MA, Kalantri S (2012) Insecticidal effect of silica and silver nanoparticles on the cowpea seed beetle, Callosobruchus maculatus F. (Col.: Bruchidae). J Entomol Res 4:297-305

Shah V, Belozerova I (2009) Influence of metal nanoparticles on the soil microbial community and germination of lettuce seeds. Water Air Soil Pollut 197:143-148

Singh SR, Jackai LEN (1985) Insect pests of cowpea in Africa: their life cycle, economic importance and potential for control. In: Singh SR, Rachie KO (eds) Cowpea research, production and utilization. Wiley, Chichester, pp 217-231

Wierzbicka M, Obidzinska J (1998) The effect of lead on seed imbibitions and germination in different plant species. Plant Sci 137:155-171

Voigt D, Peisker H, Gorb S (2009) Visualization of epicuticular grease on the covering wings in the colorado potato beetle: a scanning probe approach. In: Bhushan B, Fuchs H, (eds). In Applied scanning probe methods XIII. Nano Science and Technology, Heidelberg, Springer pp 1-16

Yang FL, Li XG, Zhu F, Lei CL (2009) Structural characterization of nanoparticles loaded with garlic essential oil and their insecticidal activity against Tribolium castaneum (Herbst) (Coleoptera: Tenebrionidae). J Agric Food Chem 57:10156-10162 